\title{
Effects of recreational football performed once a week (1 h per 12 weeks) on cardiovascular risk factors in middle-aged sedentary men
}

\section{Marco Beato, Giuseppe Coratella, Federico Schena \& Franco M. Impellizzeri}

To cite this article: Marco Beato, Giuseppe Coratella, Federico Schena \& Franco M. Impellizzeri (2017): Effects of recreational football performed once a week ( $1 \mathrm{~h}$ per 12 weeks) on cardiovascular risk factors in middle-aged sedentary men, Science and Medicine in Football

To link to this article: http://dx.doi.org/10.1080/24733938.2017.1325966

Published online: 23 May 2017.

Submit your article to this journal $\sqsubset$

a)

View related articles $₫$

View Crossmark data ¿ 


\title{
Effects of recreational football performed once a week (1 h per 12 weeks) on cardiovascular risk factors in middle-aged sedentary men
}

\author{
Marco Beato $^{\mathrm{a}, \mathrm{b}}$, Giuseppe Coratellac, Federico Schena ${ }^{\mathrm{b}}$ and Franco M. Impellizzeri ${ }^{\mathrm{d}}$ \\ ${ }^{a}$ Department of Science and Technology, University of Suffolk, Ipswich, UK; ${ }^{b}$ Department of Neurological and Movement Sciences, University of

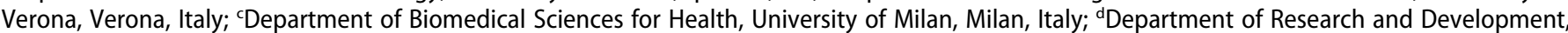 \\ Schulthess Clinic, Zurich, Switzerland
}

\begin{abstract}
Objectives: It is well established that there is a strong relationship between physical activity, cardiovascular diseases and mortality. Regular recreational football training can lower blood pressure, heart rate at rest, fat percentage, $\mathrm{LDL}$ cholesterol and increase maximal aerobic power $\left(\mathrm{VO}_{2 \mathrm{max}}\right)$. This study analyzed the effect of one recreational football training per week on middle-aged men.

Design: Randomized controlled trial.

Methods: Twenty-four participants (mean \pm SDs; age $44.5 \pm 4.7$ years, weight $81.9 \pm 10.4 \mathrm{~kg}$, height $175.0 \pm 7.3 \mathrm{~cm}$ ) were randomized in a football group (FG = 10) and control group $(\mathrm{CG}=14)$. FG performed supervised recreational football training (five-a-side futsal match) on $36 \times 18.5 \mathrm{~m}$ synthetic indoor and outdoor field, 60 min per week over 12 weeks.

Results: After training, $\mathrm{VO}_{2 \max }$ and maximal aerobic speed improved in FG respectively of $4.4 \%(+1.89$ $\left.\mathrm{mL} \mathrm{O} \cdot \mathrm{kg}^{-1} \cdot \mathrm{min}^{-1}, P=0.002\right)$ and $5.9 \%(P=0.01)$. Systolic and mean blood pressure decreased respectively of $2.5 \%(-3.18 \mathrm{mmHg}, P=0.04)$ and $2.2 \%(-2.28 \mathrm{mmHg}, P=0.04)$ in $\mathrm{FG}$, while diastolic blood pressure did not change $(-1.84 \mathrm{mmHg}, P=0.09)$.

Conclusions: Recreational football activity produces health benefits by improving $\mathrm{VO}_{2}$ max and lowering blood pressure parameters in middle-aged men.
\end{abstract}

ARTICLE HISTORY

Accepted 26 February 2017

\section{KEYWORDS}

Soccer; futsal; cardiovascular diseases; health; prevention; sedentary

\section{Introduction}

Based on the World Health Organization, sedentary lifestyle causes about 1.9 million deaths per year worldwide (Hamer \& Chida 2008). It is well established that there is a strong relationship among physical activity, cardiovascular diseases and mortality (Barlow et al. 2012). For this reason, the American College of Sport Medicine (ACSM) has recommended that adults aged 18-65 years should engage at least 150 min of moderate-intensity (between $55 \%$ and $65 \%$ of an individual maximal heart rate $\left.\mathrm{HR}_{\max }\right)$ physical activity per week to improve their health status (Garber et al. 2011). The lack of time is the major barrier to a regular active lifestyle in general population (Reichert et al. 2007). Nevertheless, sedentary people could also get some health benefits with a lower amount of training volume than recommended by the international guidelines (Lee 2007). It is widely accepted that a dose-response relationship exists between training volume and positive health adaptations (Lee 2007), but scarce literature is available about the necessary minimal amount of it, especially for activities like football or game sport in general (Garber et al. 2011).

Football is a very popular sport in Western nations (Krustrup et al. 2009), and its popularity may be used for increasing the intrinsic motivation and hence the adherence to physical activity (Ottesen et al. 2010). At recreational level, it is known that people usually practice football only once or twice per week for approximately $1 \mathrm{~h}$ per session, which also corresponds to the time that the pitch is rented but this weekly volume has not been previously investigated (Beato, Impellizzeri et al. 2016). Furthermore, recreational players commonly reduce the size of the pitch and the number of players since it is easier to arrange smaller groups for friendly matches. Therefore, five-a-side football (futsal) is the most common form of recreational football and may be a valid alternative to continuous running exercise in order to improve cardiovascular fitness (Castagna et al. 2007). In detail, futsal is played on smaller pitch than football (e.g., $40 \times 20 \mathrm{~m}$ ), a smaller ball is used (size 4) and matches are played between team of five players each (Beato, Coratella et al. 2016).

Various studies have reported that football is an effective physical activity for inducing cardiovascular benefits (Krustrup, Aagaard, et al. 2010; Krustrup et al. 2013). Previous researchers (Krustrup et al. 2009) found that regular football training (when performed two or three times a week) induces lowering blood pressure, as well as heart rate (HR) at rest, fat percentage, low-density lipoprotein (LDL) cholesterol, and increases lean body mass as well as maximal aerobic power $\left(\mathrm{VO}_{2 \max }\right.$ ) (Milanović et al. 2015; Oja et al. 2015). Other evidences reported that 6 months of football training for $1 \mathrm{~h}$ twice a week induced significant improvements in cardiac structure and function in formerly inactive men with mild-tomoderate arterial hypertension (Andersen et al. 2014). Another study reported that football training after 12-16 weeks is able to increase $\mathrm{VO}_{2 \max }$ and muscle mass equivalently or greater 
than running-based training (Krustrup, Dvorak, et al. 2010; Milanović et al. 2015).

Total energy expenditure (EE) is one of the most important components of an exercise program for health promotion (Ainsworth et al. 2011). Recent evidence has reported that one, two and three sessions per week are almost equivalent to $50 \%$ (634 kcal), 100\% (1268 kcal) and 150\% (1902 kcal) EE, respectively, as suggested in international guidelines (Beato, Impellizzeri, et al. 2016). Despite the popularity and wide appeal of this sport, no one has investigated the effect of one session per week on middle-aged male players (the most common practice). This study gives practical information to the development of preventive health programs using a small dose of football training.

The aim of this study is therefore to assess the effect of an 1 $h$ recreational football session per week, hypothesizing that this volume, after 12 weeks, will give meaningful positive changes on cardiovascular risk factors in healthy individuals.

\section{Methods}

Twenty-eight sedentary participants were initially considered during enrollment process, but four were excluded during medical screening (ECG test). Twenty-four healthy male participants without specific pathologies (assessed by medical screening) were enrolled in this study (mean \pm SDs; age $44.5 \pm 4.7$ years, weight $81.9 \pm 10.4 \mathrm{~kg}$, height $175.0 \pm 7.3 \mathrm{~cm}$ ). All participants were informed about the potential risks of the study and signed an informed consent. Twenty participants completed the study, while two participants of the football group (FG) dropped out due to injuries to their hamstring and Achilles tendon, respectively, and two participants of the control group (CG) dropped out for job-related reasons (e.g., lack of time). CONSORT (Consolidated Standards of Reporting Trials) participant flow is reported in Figure 1 (Moher et al. 2001). Adherence recorded in this randomized controlled trial (RCT) was 83\% (Zhang et al. 2014). All procedures were approved by the Ethics Committee of the Department of Neurological and Movement Sciences, University of Verona (Italy), and conducted according to the Declaration of Helsinki for human studies of the World Medical Association.

\section{Enrollment}

Potential participants were recruited through the main communication channels available at the university such as newspapers, television, web ads and flyers. Participants completed the Physical Activity Readiness Questionnaires and the International Physical Activity Questionnaire to assess their level of compatibility with the training program and to ensure the absence of regular physical exercise in the last period (Shephard 1988; Lee et al. 2011). No-active lifestyle was defined as a lack of regular activity in the last year, up to three times per week at moderate intensity $(<20$ min per session) (Krustrup et al. 2009). Participants were categorized into risk categories based on ACSM guidelines (Thompson \& ACSM 2009) and we included only those belonging to the lowand medium-risk categories. No economic incentives were provided.

\section{Study design}

In this study, we used an RCT design. The randomization was performed according to a computer-generated sequence. The participants were randomized in an FG (= 10 participants) and a CG (= 14 participants) in order to obtain the correct number of participants for recreational football matches. After the randomization, baseline differences were tested by $t$-tests without finding any statistical difference. The FG performed recreational football training once per week over 12 weeks. The CG did not perform any training during the experimental period (Krustrup et al. 2013). Outcome measures were assessed before and after the experimental period. $\mathrm{VO}_{2 \max }$ is an independent and strong predictor of cardiovascular risk factors (Lakka et al. 2003; Kodama et al. 2009). 1/2 MET (metabolic equivalent) of improvement corresponds to a decrement of $7.9 \%$ of mortality risk reduction (Blair et al. 1995; Kodama et al. 2009).

\section{Interventions}

Participants completed recreational futsal matches on a synthetic indoor or outdoor field $(36 \times 18.5 \mathrm{~m})$. The training lasted 12 weeks (60 min per session) with all the matches played in the evening (at 8.00 p.m.). Before recreational matches, participants completed a standardized 5-min warm-up followed by 55 min of matches. Five players on the same team, in turn, acted as goalkeeper (changes from goalkeeper to players every $5 \mathrm{~min}$ ). Researchers asked both FG and CG to maintain their normal lifestyle and nutrition behaviors throughout the duration of the protocol.

\section{Testing procedures}

The first day, after the medical screening, participants completed a $\mathrm{VO}_{2}$ familiarization (submaximal) test on a treadmill. On the second day, anthropometrical measurements, blood pressure and $\mathrm{HR}$ at rest and blood sampling were completed. The third day consisted of participants completing the maximal incremental test on the treadmill. Participants were asked to avoid any heavy physical activity on the day prior to testing and to refrain from caffeine $8 \mathrm{~h}$ before testing. After 12 weeks of training, all participants were retested with the same protocol. Medical doctors and assessor that administered the interventions and assessed the outcomes were blinded.

\section{Maximal aerobic power}

A maximal running incremental test was used to determine $\mathrm{VO}_{2 \max }$ (primary outcome), maximal aerobic speed (MAS), $\mathrm{HR}_{\text {max }}$ and $\mathrm{HR}-\mathrm{VO}_{2}$ relation. In this study, $\mathrm{VO}_{2 \max }$ was considered the primary outcome because it was demonstrated that low levels of cardiovascular fitness are associated with an increase in cardiovascular risk factor (Blair et al. 1995; Kodama et al. 2009). Moreover, it can be considered an important and independent factor for the prevention of cardiovascular diseases (Kodama et al. 2009; Eriksen et al. 2016). An automated metabolic cart was used to measure respiratory parameters breath-by-breath (Quark b2, Cosmed, Italy). The running 


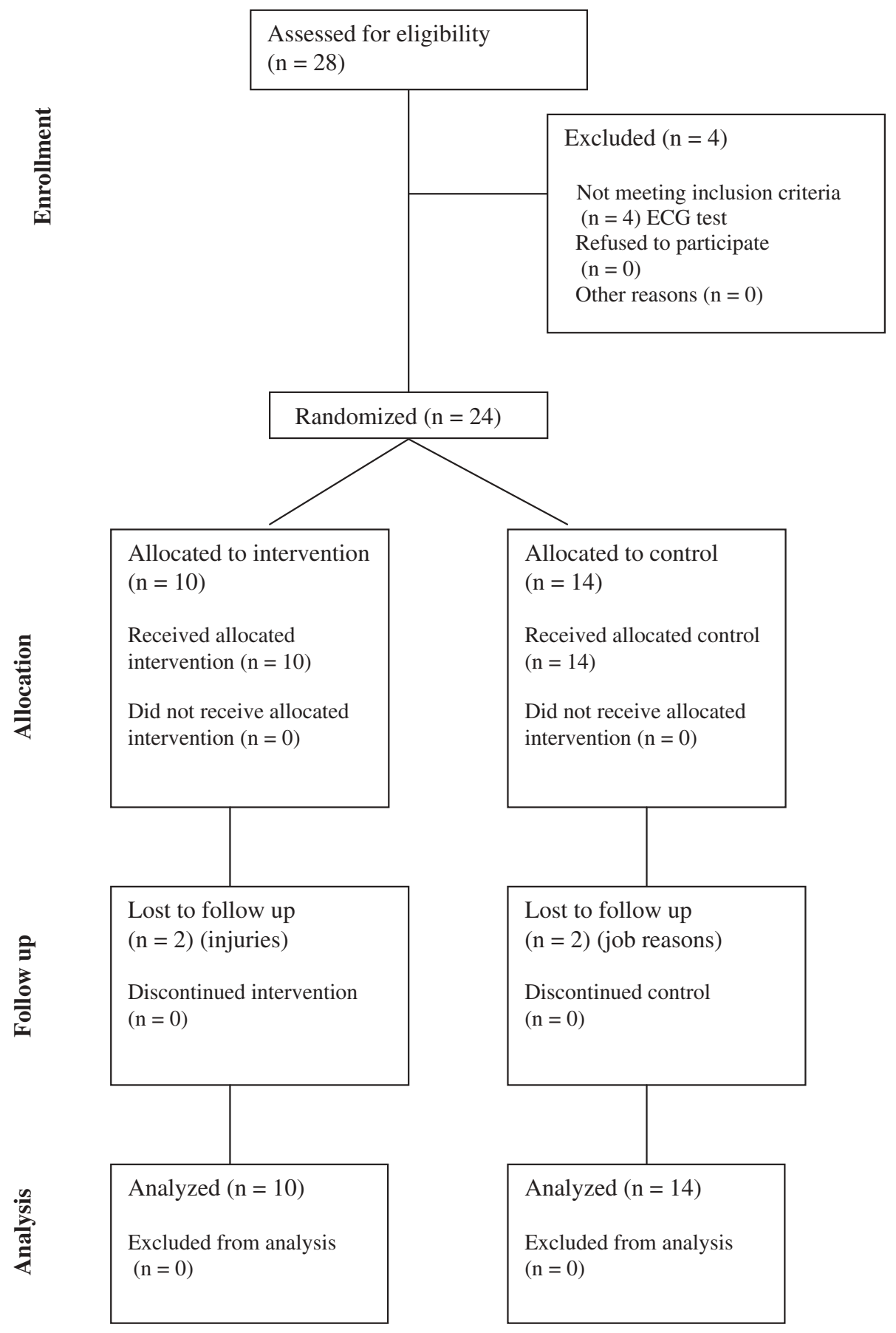

Figure 1. CONSORT diagram showing the flow of participants through each stage of a randomized trial.

protocol consisted of $3 \mathrm{~min}$ at $9 \mathrm{~km} \cdot \mathrm{h}^{-1}$ and speed increments of $0.5 \mathrm{~km} \cdot \mathrm{h}^{-1}$ every minute until exhaustion. The criteria for achieving $\mathrm{VO}_{2 \max }$ were respiratory exchange ratio (RER) $>1.10$, an HR within 10 beats $\min ^{-1}$ of the maximal level predicted by age and an rate of perceived exertion (RPE) score (CR 10 Borg scale) higher than 8 (Beato, Impellizzeri, et al. 2016).

\section{Blood pressure, HR at rest and blood analysis}

Blood pressure, $\mathrm{HR}_{\text {rest }}$ and blood analysis were assessed on the morning of day 1 and participants were asked to fast from midnight onwards the night before these measurements were recorded. $\mathrm{HR}_{\text {rest }}$ was measured using a cardio polar (Polar S610i, Polar Electro Oy, Kempele, Finland). Blood pressure was measured using a sphygmomanometer (Heine, Germany). After $10 \mathrm{~min}$ at rest in supine position, the average $\mathrm{HR}$ was recorded during the last $3 \mathrm{~min}$, while the assessment of systolic blood pressure (SBP), diastolic blood pressure (DBP) and mean blood pressure $(\mathrm{MBP}=1 / 3 \mathrm{SBP}+2 / 3 \mathrm{DBP})$ was carried out five times and the mean value was used for the analyses (Krustrup et al. 2013). Blood samples were obtained by veins in the participants' arms in the morning and stored in blood tubes containing K2EDTA (Terumo Europe N.V., Leuven, 
Belgium). The blood samples were immediately transported to the local laboratory where they were stored in controlled conditions of temperature and humidity. The analysis was performed on Advia 2120 (Siemens Healthcare Diagnostics, Tarrytown, NY, USA), which included measurement of triglycerides (TGs), fasting glucose, cholesterol LDL (LDL-C), HDL (high-density lipoprotein)-C, HDL/LDL-C ratio, total leucocyte count (WBC), total red cell count (RBC), hemoglobin concentration (HGB) and total platelet count (PLT) (Mann et al. 2014). The analysis of blood specimens was concluded within $2 \mathrm{~h}$ after sample collection.

\section{Anthropometric parameters}

Body fat estimation was determined using a skinfold-based method (skinfold calibre, Gima S.p.A., MI, Italy). Skinfolds were measured in seven different sites: triceps, subscapular, midaxillary, chest, suprailiac, abdomen and anterior thigh; body density was calculated using the Jackson and Pollock equation (Jackson \& Pollock 1978). We also recorded body weight (BW), height by Stadiometer (Seca, Italy) and body mass index (BMI). The measures were obtained three times using the average value for the analysis.

\section{Statistical analysis}

The analysis was performed using an intention-to-treat analysis that involved all the participants as originally randomized and used the baseline values for the follow up (Ellenberg 1996). Shapiro-Wilk test was used for checking the normality (assumption). The effect of the training protocols (FG and CG) and the time of testing (Pre-Post) on the outcome measure parameters were analyzed using a two-way analysis of variance (ANOVA) for repeated measures. We evaluate the effect of training by analysis of covariance (ANCOVA) considering $\mathrm{VO}_{2 \max }$ and blood pressure baseline values as covariates. Before ANCOVA analysis, baseline values (FG and CG) were tested without finding any statistical difference (temporal additivity assumption). When significant $F$-values were found, post hoc analysis was performed (Tukey). Data were presented as mean \pm SD. We also reported the mean difference with corresponding confidence interval $(95 \% \mathrm{Cl})$. The $P$ values were reported to indicate the strength of the evidence. Effect size (ES) was also calculated to evaluate time and training effect, and values of $0.01,0.06$ and $>0.15$ were considered small, medium and large, respectively (Levine \& Hullett 2002). Statistical analyses were performed by SPSS software version 20 for Windows 7, Chicago, USA.

\section{Results}

\section{Aerobic power}

A meaningful interaction time-group (ANOVA) was found for $\mathrm{VO}_{2 \max }$ and MAS after 12 training weeks, $F=8.70, P=0.007$, $\mathrm{ES}=0.80$ (large) and $F=5.84, P=0.024, \mathrm{ES}=0.64$ (large). $\mathrm{VO}_{2 \max }$ and MAS improved in FG respectively of $4.4 \%(t=4.31, P=0.002$, mean difference $1.89,95 \% \mathrm{Cl}(0.90$ to 2.88$) \mathrm{mL} \mathrm{O}_{2} \cdot \mathrm{kg}^{-1} \cdot \mathrm{min}^{-1}$.) and $5.95 \%(t=3.28, P=0.01$, mean difference $0.7,95 \% \mathrm{Cl}(0.22$ to
1.18) $\mathrm{km} \cdot \mathrm{h}^{-1}$ ) at the contrary $\mathrm{HR}_{\text {max }}, \mathrm{RPE}$ and $R$ did not change over the period $(P>0.05)$. A meaningful interaction time-group (ANCOVA) was found for $\mathrm{VO}_{2 \text { max }}$ and MAS taking baseline values as covariates, $F=10.4, P=0.004$ and $F=5.8, P=0.02$, respectively. CG did not record any meaningful variations $(P>0.05)$ (Table 1$)$. No between-group interaction was found between FG and CG at baseline level for any variables, but meaningful differences were found after the treatment in $\mathrm{VO}_{2 \max }(P=0.014)$ in $\mathrm{FG}(45.06 \mathrm{~mL}$ $\left.\mathrm{O}_{2} \cdot \mathrm{kg}^{-1} \cdot \mathrm{min}^{-1}\right)$ compared to $\mathrm{CG}\left(41.05 \mathrm{~mL} \mathrm{O} \cdot \mathrm{kg}^{-1} \cdot \mathrm{min}^{-1}\right)$.

\section{Blood pressure}

A time-group meaningful interaction (ANOVA) was found after 12 training weeks in SBP and $\mathrm{MBP}$, respectively, $F=8.71$, $P=0.007, \mathrm{ES}=0.80$ (large) and $F=7.65, P=0.011, \mathrm{ES}=0.75$ (large) with decreased SBP and MBP of $2.5 \%(t=2.392$, $P=0.04$, mean difference $-3.18 \mathrm{mmHg}, 95 \% \mathrm{Cl}(-0.17$ to $-6.19))$ and $2.2 \%(t=-2.28, P=0.044$, mean difference $-2.28 \mathrm{mmHg}, 95 \% \mathrm{Cl}(-0.08$ to -4.47$))$ respectively in $\mathrm{FG}$, while DBP did not change during protocol period $(P=0.09$, mean difference $-1.84,95 \% \mathrm{Cl}(0.48$ to -4.16$) \mathrm{mmHg})$. A meaningful interaction time-group (ANCOVA) was found for SBP and MBP taking baseline values as covariates, $F=6.79$, $P=0.017$ and $F=7.12, P=0.02$, respectively. $C G$ did not show any meaningful variation over the protocol period (Table 1). No between-group interactions were found between FG and CG at baseline level for any variables as well as after the treatment.

\section{Anthropometric analysis and blood analysis}

In both FG and CG, we did not observe any variation in anthropometric parameters, as well as in blood variables (Table 2).

Table 1. Summary of physiological and anthropometrical data before and after 12 weeks of recreational football practice ( $F G, n=10$ and $C G, n=14$ ).

\begin{tabular}{|c|c|c|c|c|}
\hline & FG pre & FG post & CG pre & CG post \\
\hline Age (years) & $42.9 \pm 4.2$ & & $45.6 \pm 4.8$ & \\
\hline Height (m) & $175.1 \pm 6.7$ & & $174.9 \pm 7.9$ & \\
\hline BW (kg) & $82.1 \pm 10.7$ & $82.2 \pm 11.2$ & $81.8 \pm 10.6$ & $82.0 \pm 10.5$ \\
\hline Fat mass $(\%)$ & $18.5 \pm 3.8$ & $18.3 \pm 3.6$ & $20.2 \pm 3.4$ & $20.7 \pm 3.6$ \\
\hline BMI & $26.7 \pm 2.8$ & $26.8 \pm 2.9$ & $26.7 \pm 2.6$ & $26.8 \pm 2.7$ \\
\hline $\begin{array}{l}\mathrm{VO}_{2 \max } \\
\quad(\mathrm{mL} \\
\left.\quad \mathrm{O}_{2} \cdot \mathrm{kg}^{-1} \cdot \mathrm{min}^{-1}\right)\end{array}$ & $43.2 \pm 4.4$ & $45.1 \pm 4.6^{*}$ & $41.5 \pm 3.1$ & $41.1 \pm 2.8$ \\
\hline RER & $1.12 \pm 0.03$ & $1.11 \pm 0.02$ & $1.12 \pm 0.03$ & $1.11 \pm 0.03$ \\
\hline $\operatorname{MAS}\left(\mathrm{km} \cdot \mathrm{h}^{-1}\right)$ & $11.8 \pm 1.3$ & $12.5 \pm 1.3^{*}$ & $11.5 \pm 1.1$ & $11.6 \pm 1.3$ \\
\hline $\mathrm{HR}_{\text {max }}(\mathrm{bpm})$ & $178 \pm 11$ & $173 \pm 12$ & $176 \pm 10$ & $173 \pm 13$ \\
\hline RPE & $8.0 \pm 1.2$ & $8.0 \pm 0.8$ & $8.1 \pm 0.9$ & $7.9 \pm 0.7$ \\
\hline $\mathrm{SBP}(\mathrm{mmHg})$ & $132 \pm 9$ & $129 \pm 9^{*}$ & $128 \pm 14$ & $130 \pm 13$ \\
\hline $\mathrm{DBP}(\mathrm{mmHg})$ & $90 \pm 7$ & $88 \pm 5$ & $88 \pm 9$ & $89 \pm 9$ \\
\hline $\mathrm{MBP}(\mathrm{mmHg})$ & $104 \pm 7$ & $101 \pm 6^{*}$ & $101 \pm 10$ & $103 \pm 10$ \\
\hline $\mathrm{HR}_{\text {rest }}(\mathrm{bpm})$ & $59 \pm 9$ & $57 \pm 3$ & $62 \pm 6$ & $62 \pm 7$ \\
\hline
\end{tabular}

All data are presented in mean \pm SDs.

* $P<0.05$ pre compared to post.

BW: body weight; BMI: body mass index; RER: respiratory exchange ratio; $\mathrm{HR}_{\text {max }}$ : maximum heart rate; $\mathrm{VO}_{2 \text { max }}$ maximal aerobic power; MAS: maximal aerobic speed; RPE: rate of perceived exertion; SBP: systolic blood pressure; DBP: diastolic blood pressure; MBP: mean blood pressure. 
Table 2. Summary of blood analysis before and after 12 weeks of recreational football practice (FG, $n=10$ and CG, $n=14$ ).

\begin{tabular}{|c|c|c|c|c|}
\hline & FG pre & FG post & CG pre & CG post \\
\hline Hematocrit $\left(L \cdot L^{-1}\right)$ & $0.46 \pm 0.03$ & $0.46 \pm 0.02$ & $0.45 \pm 0.02$ & $0.45 \pm 0.02$ \\
\hline $\mathrm{HGB}\left(\mathrm{g} \cdot \mathrm{L}^{-1}\right)$ & $152.2 \pm 11.2$ & $151.9 \pm 9.4$ & $150.7 \pm 9.1$ & $150.3 \pm 9.2$ \\
\hline $\operatorname{RBC}\left(10^{12} \mathrm{~L}^{-1}\right)$ & $5.01 \pm 0.49$ & $5.02 \pm 0.41$ & $5.23 \pm 0.43$ & $5.12 \pm 0.32$ \\
\hline $\operatorname{PLT}\left(10^{9} \mathrm{~L}^{-1}\right)$ & $227.4 \pm 56.6$ & $220.8 \pm 44.0$ & $222.8 \pm 48.4$ & $213.3 \pm 33.8$ \\
\hline WBC $\left(10^{9} \mathrm{~L}^{-1}\right)$ & $6.29 \pm 1.45$ & $6.65 \pm 1.43$ & $6.29 \pm 2.8$ & $6.27 \pm 1.57$ \\
\hline $\mathrm{FA}\left(\mathrm{mg} \cdot \mathrm{dL}^{-1}\right)$ & $90.1 \pm 13.8$ & $86.9 \pm 8.9$ & $92.0 \pm 11.3$ & $86.9 \pm 10.5$ \\
\hline Total-C $\left(\mathrm{mg}^{-1}\right)$ & $195 \pm 36$ & $183 \pm 33$ & $216 \pm 34$ & $214 \pm 33$ \\
\hline $\mathrm{HDL}-\mathrm{C}\left(\mathrm{mg} \cdot \mathrm{dL}^{-1}\right)$ & $56 \pm 14$ & $53 \pm 12$ & $50 \pm 9$ & $49 \pm 8$ \\
\hline $\mathrm{LDL}-\mathrm{C}\left(\mathrm{mg} \cdot \mathrm{dL}^{-1}\right)$ & $111 \pm 31$ & $101 \pm 18$ & $143 \pm 32$ & $144 \pm 31$ \\
\hline $\mathrm{TG}\left(\mathrm{mg} \cdot \mathrm{dL}^{-1}\right)$ & $130.3 \pm 76.1$ & $128.2 \pm 78.2$ & $121.6 \pm 40.1$ & $115.6 \pm 44.4$ \\
\hline
\end{tabular}

All data are presented in mean \pm SDs.

${ }^{*} P<0.05$ pre compared to post.

TG: triglycerides; FA: fasting glucose; LDL-C: cholesterol LDL; HDL-C: cholesterol HDL; Total-C: total cholesterol; WBC: total leucocyte count; RBC: total red cell count; HGB: hemoglobin concentration; PLT: total platelet count.

\section{Discussion}

To our knowledge, this is the first study examining the effect of an $1 \mathrm{~h}$ recreational football session per week on cardiovascular risk factors in middle-aged men. As hypothesized, we found that 12 weeks of recreational football decreased some cardiovascular risk factors and specifically increased $\mathrm{VO}_{2 \text { max }}$ as well as decreased SBP and MBP. This study also supports previous findings that even a low training volume is important and enough to give some meaningful improvements on health parameters in middle-aged male participants (Lee 2007; Beato, Impellizzeri, et al. 2016). Therefore, people with limited free time for performing physical activity (the lack of time is one of the major barriers to a regular active lifestyle in general population) can play recreational football once a week to improve their health status (Reichert et al. 2007). However, these observed changes are possible with such training volume, but they are less pronounced than in previous football studies with more frequent training and a higher training volume (Bangsbo et al. 2015; Milanović et al. 2015).

In this study, we used the $\mathrm{VO}_{2 \max }$ as the main outcome given it has been demonstrated that low levels of cardiovascular fitness are associated with an increase in cardiovascular risk factor (Kodama et al. 2009). We considered $1 / 2$ MET the value corresponding to the minimum meaningful improvement, which is an improvement producing a decrement of cardiovascular risk factors. Indeed, $1 / 2$ MET and 1 MET of increment corresponds to $7.9 \%$ and $13 \%$ reduction in risk mortality, respectively (Blair et al. 1995; Kodama et al. 2009). According to our hypothesis, after 12 weeks of recreational football, participants improved their $\mathrm{VO}_{2 \max }$ by $4.4 \%$, corresponding to $1.9 \mathrm{~mL} \mathrm{O} \cdot \mathrm{kg}^{-1} \cdot \mathrm{min}^{-1}$; moreover, meaningful differences were found at the end of the treatment about $\mathrm{VO}_{2 \max }$ in $\mathrm{FG}$ compared to CG (45.06 and $41.05 \mathrm{~mL} \mathrm{O} \cdot \mathrm{kg}^{-1} \cdot \mathrm{min}^{-1}$, respectively). This result is half the improvement shown in a recent study (Krustrup et al. 2013), in which the authors found an increase of $2.8 \mathrm{~mL} \mathrm{O} \cdot \mathrm{kg}^{-1} \cdot \mathrm{min}^{-1}(9 \%)$ after 6 months of football training performed twice per week. Assuming a dose-response relation as suggested by the study of Church et al. (2007), the difference between the current and the previous study may be justified by the different doses of physical activity (lower in the current study). Moreover, recent literature supports the general validity of recreational football as reported by Milanović et al. (2015) that showed the meta-analyzed effect $(E S=1.22$, large $)$ on $\mathrm{VO}_{2 \max }$ of recreational football in men compared to controls. Based on this meta-analysis, football is effective for improving maximal aerobic capacity and general fitness parameters after short to medium training periods, as reported in another recent revision (Milanović et al. 2015; Oja et al. 2015). These findings are aligned with the results recorded in this study that show a medium ( $E S=0.80$, large) training effect on $\mathrm{VO}_{2 \max }$ after 12 weeks of training (Bangsbo et al. 2015; Milanović et al. 2015; Oja et al. 2015).

SBP and MBP decreased after the training period which confirms the positive effects a low volume of recreational football can have on blood pressure $(E S=0.8$ and 0.75 , large respectively). Krustrup et al. (2013) suggested that football can be used as a nonpharmacological treatment of hypertension in middle-aged men and that this activity may be even better than the pharmacological approach. This study reported an improvement of 13 and $8 \mathrm{mmHg}$ in SBP and DBP, respectively (Krustrup et al. 2013). These values are much higher for hypertensive men. Nevertheless, the improvements found in the current study are comparable to the 3 and $2 \mathrm{mmHg}$ reported in normotensive male population after 12 weeks of endurance training (Fagard 2001). The population enrolled in this study is healthy, thus generally normotensive. It needs to be considered that our sample was influenced by the exclusion, during medical screening, of four participants of the 28 initially considered during the enrollment process (Figure 1). The small reduction of blood pressure reported in our study can be explained by the inclusion of normotensive participants, and this is supported by Bangsbo et al. (2015), who reported that blood pressure was not reduced in some previous studies due to the inclusion on healthy participants. Moreover, a doseresponse effect may be associated with blood pressure reduction. This study utilized a protocol of $1 \mathrm{~h}$ per week that probably has a smaller effect than previous studies proposing 2 or 3 h per week (Krustrup, Aagaard, et al. 2010; Bangsbo et al. 2014).

There were no substantial and significant changes in both blood and anthropometrical parameters (Tables 1 and 2). A dose-response relationship does exist between the amount of exercise and fitness (Lee 2007). Thus, to find greater improvements, it may be necessary to administrate a heavier recreational football dose such as two or three training sessions per week as reported in previous studies (Bangsbo et al. 2014, 2015; Beato, Impellizzeri, et al. 2016). The reason that we did not find any improvement in blood analysis could be explained by the low training volume proposed and by the blood clinically normal baseline levels (Fagard 2001; Bangsbo et al. 2014). Furthermore, other previous studies, involving 2-3 training sessions per week, did not found meaningful variations after the protocol period in untrained male (age range 31-54 years) (Andersen et al. 2010; Krustrup et al. 2013). Generally, it is reported an improvement on LDL-C and total$C$ after a period of recreational football training, while many other studies have not found meaningful effects (Bangsbo et al. 2015). In this study, we found no statistical trend in both total-C (from $195 \pm 36$ to $183 \pm 33 \mathrm{mg} \cdot \mathrm{dL}^{-1}$ ) and LDL-C (from $111 \pm 31$ to $101 \pm 18 \mathrm{mg} \cdot \mathrm{dL}^{-1}$ ). It is important to 
underline that blood and anthropometric parameters are closely associated with nutrition strategies (Torger et al. 2012; Mann et al. 2014). It is well documented that exercise without dietary intervention has a small capacity to reduce weight and fat percentage, as well as a small effectiveness on blood parameters (Church et al. 2007).

This study has some limitations. The first limitation is associated to the lack of nutritional and physical activity control in both FG and CG. Participants were asked to continue their usual diet and to avoid starting any other physical activity programs, but we did not monitor their nutritional intake and we could not monitor the activity completed outside the training sessions. This might have affected the training effect on blood and anthropometric parameters. The findings of this study cannot necessarily be extended to other specific populations. Therefore, future studies should examine the effects of low volume recreational football on middle-aged women and younger or older individuals. Moreover, real dose-response concurrently comparing the effects of different doses of exercise (e.g., none, one and two sessions per week) is necessary. This study is the first that compares football training volume ( $1 \mathrm{~h}$ a week) versus control. Future studies could compare the effect of such training versus running-based methods on cardiovascular risk factors. Previous studies reported that football training was able to improve $\mathrm{VO}_{2 \max }$ better than running training (13\% and $8 \%$, respectively) as well as for other physiological parameters associated with health (e.g., SBP, DBP, etc.) (Krustrup et al. 2009; Krustrup, Aagaard, et al. 2010). Finally, future studies should also examine the risk/benefit ratio of recreational football especially considering we had two injuries during the 12-week intervention. Currently, little knowledge is available regarding the relationship between recreational sports and injuries. Taking into account the high intensity of football and its characteristics (invasion sport), it is possible to suppose a higher injury risk compared to jogging and running-based activities (Krustrup, Dvorak, et al. 2010).

Recreational football, other than being an effective exercise strategy to enhance aerobic fitness and reduce cardiovascular risk factors, can improve interpersonal relationships and social skills in people. Furthermore, it can promote empathy through smaller groups allowing face-to-face communication (Krustrup et al. 2009; Ottesen et al. 2010). This is a crucial factor to improve adherence of health programs (Krustrup, Aagaard, et al. 2010). Treatment adherence may influence the therapeutic effect that is observed in an RCT. In this study, adherence was recording a value of $83 \%$, in agreement to what was previously reported in the literature (88.4\%; range: 48-100\%) (Zhang et al. 2014). After the study, participants continued the football training activity and this seems to emphasize the capacity of recreational football in improving interpersonal relationships and adherence to health programs (Bangsbo et al. 2014). While previous studies have shown that substantial benefits can be obtained by performing recreational football 2-3 times per week, the current investigation has shown that also low volume of football practice as low as $1 \mathrm{~h}$ per week can produce health benefits such as improved $\mathrm{VO}_{2 \max }$ and blood pressure in middle-aged men. This is in agreement with previous studies revealing the positive effects of physical activity performed at half the recommend ACSM quantity (Lee 2007). This study may have important implications for designing physical activity-based health programs.

\section{Practical implications}

Recreational football is an effective training modality to stimulate and improve cardiovascular fitness in healthy middle-aged men. This study shows the effect of $1 \mathrm{~h}$ recreational football session per week and suggests that a lower training volume than recommended by ACSM guidelines can give meaningful benefits. This study suggests that people with limited free time available for participating in training programs (common barrier to physical activity) can practice recreational football $1 \mathrm{~h}$ per week and still have some health benefits. However, these observed changes are less pronounced than in previous football studies with more frequent training and a higher training volume.

\section{Disclosure statement}

No potential conflict of interest was reported by the authors.

\section{References}

Ainsworth BE, Haskell WL, Herrmann SD, Meckes N, David RN, Tudor-Locke C, Greer JL, Vezina J, Whitt-Glover MC, Leon AS. 2011. Second update of codes and MET values. Med Sci Sports Exerc. 39:1575-1581.

Andersen LJ, Randers MB, Hansen PR, Hornstrup T, Schmidt JF, Dvorak J, Søgaard P, Krustrup P, Bangsbo J. 2014. Structural and functional cardiac adaptations to 6 months of football training in untrained hypertensive men. Scand J Med Sci Sports. 24:27-35.

Andersen LJ, Randers MB, Westh K, Martone D, Hansen PR, Junge A, Dvorak J, Bangsbo J, Krustrup P. 2010. Football as a treatment for hypertension in untrained 30 - 55-year-old men: a prospective randomized study. Scand J Med Sci Sports. 20:98-102.

Bangsbo J, Hansen PR, Dvorak J, Krustrup P. 2015. Recreational football for disease prevention and treatment in untrained men: a narrative review examining cardiovascular health, lipid pro fi le, body composition, muscle strength and functional capacity. Br Sournal Sports Med. 49:568-576.

Bangsbo J, Junge A, Dvorak J, Krustrup P. 2014. Executive summary: football for health - prevention and treatment of non-communicable diseases across the lifespan through football. Scand J Med Sci Sports. 24:147-150.

Barlow CE, Defina LF, Radford NB, Berry JD, Cooper KH, Haskell WL, Jones LW, Lakoski SG. 2012. Cardiorespiratory fitness and long-term survival in "low-risk" adults. J Am Heart Assoc. 1:e001354.

Beato M, Coratella G, Schena F. 2016. Brief review of the state of art in futsal. J Sport Med Phys Fitness. 56:428-432.

Beato M, Impellizzeri FM, Coratella G, Schena F. 2016. Quantification of energy expenditure of recreational football. J Sports Sci. 34:2185-2188.

Blair SN, Kohl HW 3rd, Barlow CE, Paffenbarger RSJ, Gibbons LW, Macera CA. 1995. Changes in physical fitness and all-cause mortality. JAMA. 273:1093-1098.

Castagna C, Belardinelli R, Impellizzeri FM, Abt GA, Coutts AJ, Ottavio SD. 2007. Cardiovascular responses during recreational 5 -a-side indoorsoccer. J Sci Med Sport. 10:89-95.

Church TS, Earnest CP, Skinner JS, Blair SN. 2007. Effects of different doses of physical activity on cardiorespiratory fitness among sedentary, overweight or obese postmenopausal. JAMA. 297:2081-2091.

Ellenberg JH. 1996. Intent-to-treat analysis versus as-treated analysis. Ther Innovation Regul Sci. 30:535-544.

Eriksen L, Grønbaek M, Helge JW, Tolstrup JS. 2016. Cardiorespiratory fitness in 16025 adults aged 18-91 years and associations with 
physical activity and sitting time. Scand J Med Sci Sports. 26:14351443.

Fagard RH. 2001. Exercise characteristics and the blood pressure response to dynamic physical training. Med Sci Sports Exerc. 33:S484-S492, discussion S493-4.

Garber CE, Blissmer B, Deschenes MR, Franklin BA, Lamonte MJ. 2011 Quantity and quality of exercise for developing and maintaining neuromotor fitness in apparently healthy adults: guidance for prescribing exercise. Med Sci Sports Exerc. 11:1334-1359.

Hamer M, Chida Y. 2008. Walking and primary prevention- a meta-analysis of prospective cohort studies. Br J Sports Med. 42:238-243.

Jackson A, Pollock M. 1978. Generalized equations for predicting body density of men. Br J Nutr. 40:497-504.

Kodama S, Saito K, Tanaka S, Maki M, Yachi Y, Asumi M, Sugawara, A, Totsuka, K, Shimano, H, Ohashi, Y, Yamada, N. 2009. Cardiorespiratory fitness as a quantitative predictor of all-cause mortality and cardiovascular events in healthy men and women: a metaanalysis. JAMA. 301:2012-2035.

Krustrup P, Aagaard P, Nybo L, Petersen J, Mohr M, Bangsbo J. 2010. Recreational football as a health promoting activity: a topical review. Scand J Med Sci Sports. 20:1-13.

Krustrup P, Dvorak J, Junge A, Bangsbo J. 2010. Executive summary: the health and fitness benefits of regular participation in small-sided football games. Scand J Med Sci Sports. 20:132-135.

Krustrup P, Nielsen JJ, Krustrup BR, Christensen JF, Pedersen H, Randers MB, Aagaard P, Petersen A-M, Nybo L, Bangsbo J. 2009. Recreational soccer is an effective health-promoting activity for untrained men. $\mathrm{Br} J$ Sports Med. 43:825-831.

Krustrup P, Randers MB, Andersen L, Jackman SR, Bangsbo J, Hansen PR. 2013. Soccer improves fitness and attenuates cardiovascular risk factors in hypertensive men. Med Sci Sports Exerc. 45:553-561.

Lakka TA, Laaksonen DE, Lakka HM, Männikkö N, Niskanen LK, Rauramaa R, Salonen JT. 2003. Sedentary lifestyle, poor cardiorespiratory fitness, and the metabolic syndrome. Med Sci Sports Exerc. 35:1279-1286.

Lee IM. 2007. Dose-response relation between physical activity and fitness. JAMA. 297:2137-2139.
Lee PH, Macfarlane DJ, Lam TH, Stewart SM. 2011. Validity of the international physical activity questionnaire short form (IPAQ-SF): a systematic review. Int J Behav Nutr Phys Activity. 8:115.

Levine T, Hullett C. 2002. Eta squared, partial eta squared, and misreporting of effect size in communication research. Hum Commun Res. 28:612-625.

Mann S, Beedie C, Jimenez A. 2014. Differential effects of aerobic exercise, resistance training and combined exercise modalities on cholesterol and the lipid profile: review, synthesis and recommendations. Sports Med. 44:211-221.

Milanović Z, Pantelić S, Čović N, Sporiš G, Krustrup P. 2015. Is recreational soccer effective for improving VO2max? Systematic review and meta-analysis. Sports Med. 45:1339-1353.

Moher D, Schulz KF, Altman DG, CONSORT GROUP. 2001. The CONSORT statement: revised recommendations for improving the quality of reports of parallel-group randomized trials. Ann Intern Med. 134:657662. Retrieved from: http://www.ncbi.nlm.nih.gov/pubmed/11304106

Oja P, Titze S, Kokko S, Kujala UM, Heinonen A, Kelly P, Koski P, Foster C. 2015. Health benefits of different sport disciplines for adults: systematic review of observational and intervention studies with meta-analysis. $\mathrm{Br}$ J Sports Med. 49:434-440.

Ottesen L, Jeppesen RS, Krustrup BR. 2010. The development of social capital through football and running- studying an intervention program for inactive women. Scand J Med Sci Sports. 20:118-131.

Reichert FF, Barros AJ, Domingues MR, Hallal PC. 2007. The role of perceived personal barriers to engagement in leisure-time physical activity. Am J Public Health. 97:515-519.

Shephard RJ. 1988. PAR-Q, Canadian Home Fitness Test and exercise screening alternatives. Sports Med. 5:185-195.

Thompson W, ACSM. 2009. ACSM's guidelines for exercise testing and prescription. (Edition Ei). Philadelphia (PA): Lippincott Williams and Wilkins.

Torger P, Grundvold I, Kjeldsen SE, Erikssen JE, Sandvik L, Liestøl K, Bodegard J, Pedersen TR, Bodegard J. 2012. HDL-cholesterol and prediction of coronary heart disease: modified by physical fitness? A 28-year follow-up of apparently healthy men. Atherosclerosis. 220:250-256.

Zhang Z, Peluso MJ, Gross CP, Viscoli CM, Kernan WN. 2014. Adherence reporting in randomized controlled trials. Clin Trials. 11:195-204. 